In der Rubrik "Literatur kompakt" werden die wichtigsten Originalarbeiten aus der internationalen Fachliteratur referiert.

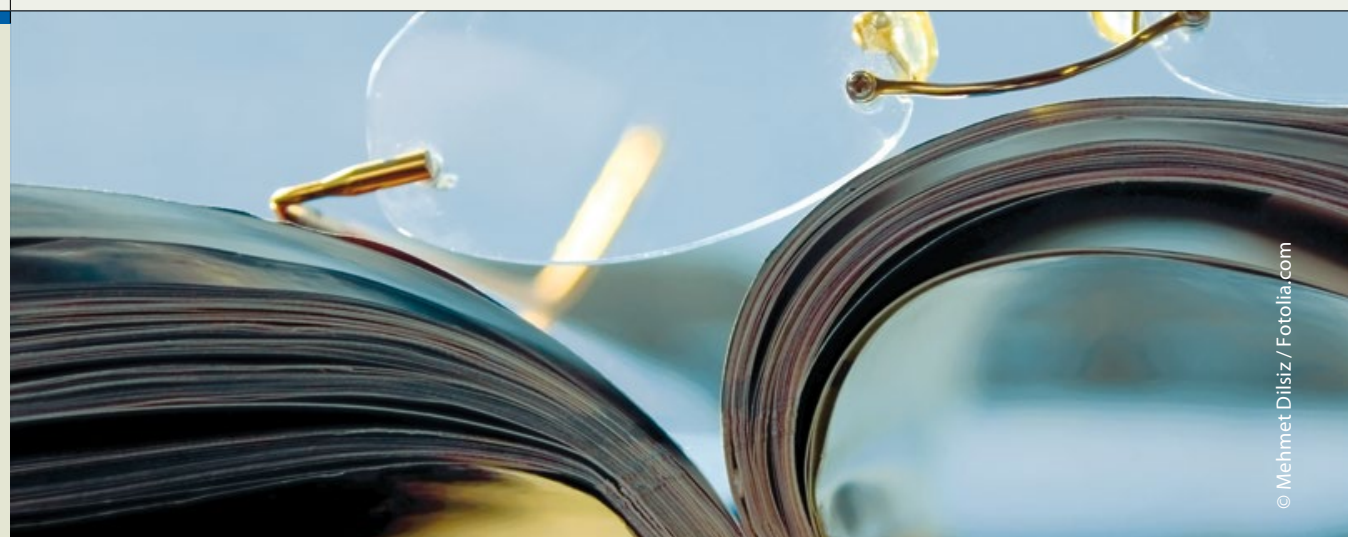

\section{Warzen: Rezidivrisiko bei Rauchern erhöht}

\author{
Warzen sind lästig. Trotz erfolgreicher Behandlung kommen sie häufig \\ wieder. Wie lässt sich das Rückfallrisiko am besten minimieren?
}

$\mathrm{M}$ an rückt ihnen auf vielerlei Arten zu Leibe: Sie werden mit Laserlicht beschossen, eingefroren oder mit Säure aufgelöst. Doch Warzen erweisen sich gegenüber therapeutischen Maßnahmen oftmals als sehr hartnäckig und kehren nach erfolgreicher Entfernung häufig wieder. Welche Faktoren das Rezidivrisiko beeinflussen, haben Dermatologen aus Italien in einer Kohortenstudie prospektiv untersucht und nach behandlungsspezifischen wie auch patientenbezogenen Risikofaktoren gefahndet.

199 Patienten wurden in vier Gruppen randomisiert. Die Probanden wurden entweder mit einem gepulsten Farbstofflaser (PDL), einem $\mathrm{CO}_{2}$-Laser, einer keratolytischen Lösung oder mit Kälte (Kryotherapie) behandelt. Teilnehmen durfte nur, wer zum ersten Mal Probleme mit Warzen an den Fußsohlen hatte.

Am schnellsten warzenfrei waren die Teilnehmer der $\mathrm{CO}_{2}$-Laser-Gruppe, im Durchschnitt nach vier Wochen. Besonders langwierig hingegen gestaltete sich die Kryotherapie. Durchschnittlich 24 Wochen lang mussten die Warzen regelmäßig vereist werden, ehe sie verschwunden waren.

Bei vielen war der Therapieerfolg von Dauer. Insgesamt 115 Teilnehmer waren 24 Wochen nach erfolgreicher Warzenentfernung weiterhin warzenfrei. Hinsichtlich des Rezidivrisikos zeigten sich

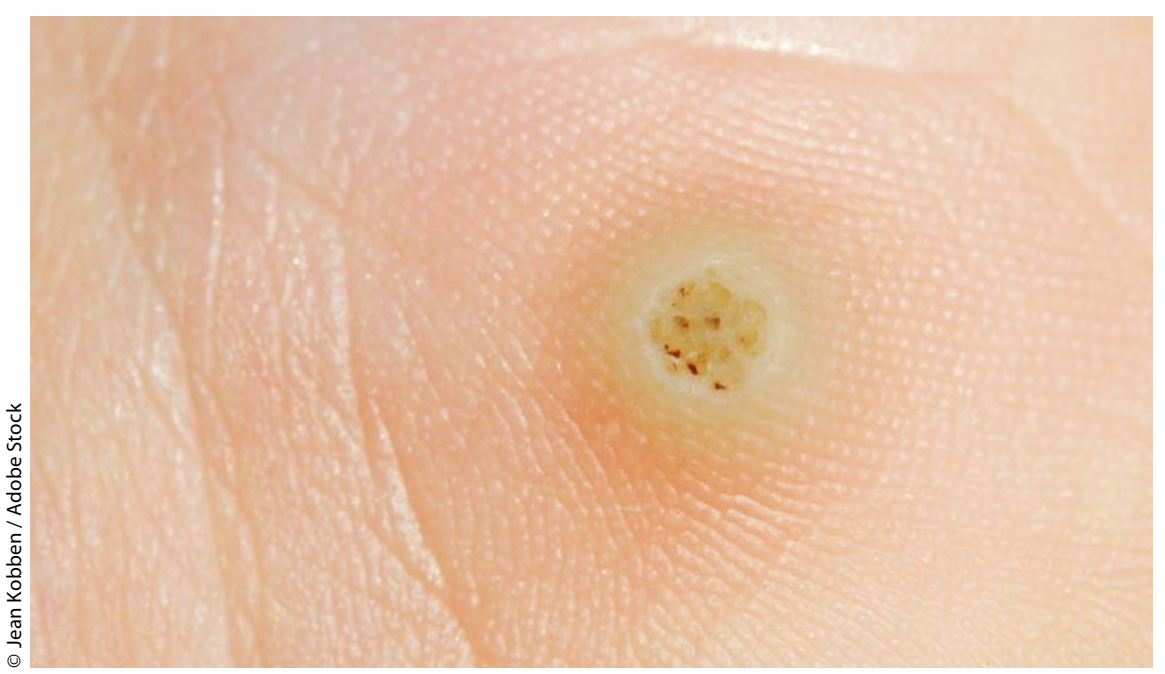

Warzen: Raucher haben ein erhöhtes Risiko für Rezidive. jedoch Unterschiede zwischen den Behandlungsmethoden. Die wenigsten Rückfälle traten nach Behandlung mit dem gepulsten Farbstofflaser auf. Nach sechs Monaten waren $74 \%$ warzenfrei geblieben. In der Keratolysegruppe betrug der Anteil nur 55,1\%, in der Kryotherapiegruppe $54,0 \%$ und in der $\mathrm{CO}_{2}$-Lasergruppe $48,0 \%$. Damit lag das Rückfallrisiko nach Keratolyse (Hazard Ratio [HR] 3,23; 95\%-Konfidenzintervall [95\%-KI] $1,60-6,54)$ oder $\mathrm{CO}_{2}$-Laserbehandlung (HR 2,92; 95\%-KI 1,49-5,74) dreimal höher als nach PDL-Behandlung.

Mit der Rückfallwahrscheinlichkeit im Zusammenhang standen darüber hinaus auch patientenbezogene Faktoren. Bei Probanden, die 26 Jahre oder älter waren, stieg das Rückfallrisiko im Vergleich zu jüngere Teilnehmern auf das Doppelte, bei Rauchern im Vergleich zu Nichtrauchern sogar auf das Fünffache.

Fazit: Die niedrigsten Rückfallquoten sind mit dem gepulsten Farbstofflaser zu erzielen. Doch angesichts der mangelnden Verfügbarkeit, der hohen Kosten und der fehlenden Therapieempfehlungen für den gepulsten Farbstofflaser sprechen sich die Studienautoren dafür aus, die anderen Verfahren auch weiterhin in der Praxis zu berücksichtigen. Gleichzeitig betonen sie den negativen Einfluss des Rauchens. Im Vergleich zu Nichtrauchern sei nicht nur die Rezidivwahrscheinlichkeit fünfmal höher, auch die Primärtherapie dauere bei Rauchern im Durchschnitt länger. Dr. Dagmar Kraus

Bencini PL et al. Risk factors for recurrence after successful treatment of warts: the role of smoking habits. J Eur Acad Dermatol Venereol 2017; 31: 712-6 